\title{
AULA MAGNA DO DOUTORADO HONORIS CAUSA EM PEDAGOGIA
}

Por Iracema Amaral, tradução para o português do Brasil do original: LUBICH, Chiara Lezione per Laurea Honoris causa in Pedagogia, Washington: 2000.

\author{
Eminência, cardeal Hichkey \\ Presidente O'Connell, \\ Arcebispo Montalvo, \\ Excelentíssimos bispos e personalidades religiosas, \\ Membros do Conselho de administração, \\ Ilustres professores e membros da comunidade Acadêmica, \\ Senhoras e senhores, queridos amigos,
}

Agradeço, com todo o coração, a esta ilustre Universidade por ter pensado em atribuir este doutorado em Pedagogia à minha pessoa e, por meio dela, ao Movimento dos Focolares. Creio que seja um reconhecimento à contribuição que teríamos dado à formação da pessoa humana e da sociedade no campo da educação. E isso porque cada tensão da nossa ação é religiosa e concentra-se sempre no esforço educativo, em Cristo, que vinculou o conceito de educador inclusive a si mesmo: «Nem queirais ser chamados mestres; porque um só é o vosso Mestre, que é o Cristo» (Mt 23,10).

Antes de começar a abordar o aspecto da educação no nosso Movimento, que é chamado também Obra de Maria, acho que é necessário, pelo menos para quem não o conhece, apresentar a espiritualidade que o anima e gera um novo estilo de vida.

A Obra de Maria é um Movimento eclesial, presente em cerca de 200 países e tem milhões de membros. As suas dimensões dizem que é Obra de Deus. Assim, de fato, a qualificam João Paulo II e a Igreja. O objetivo do Movimento é ajudar a realizar o testamento de Jesus: «Que todos sejam um» (Jo 17,21). Esse objetivo se alcança por meio dessa espiritualidade que é pessoal e comunitária ao mesmo tempo.

Suas linhas de ação se apoiam em pontos fundamentais, que são palavras ou realidades evangélicas, que se compreendem bem, ao conhecermos como o Espírito Santo as imprimiu no nosso íntimo, desde os primeiros meses da nossa nova vida.

Estávamos na Itália nos anos 40. A Segunda Guerra Mundial se agravava. Enquanto realizava um ato de caridade, senti que Deus me chamava a doar-me para sempre a Ele. 
E o fiz no dia 7 de dezembro de 1943, data que será considerada o início do Movimento. Por vários motivos, aproximei-me de jovens da minha idade que tomaram a decisão de seguir a minha estrada.

No dia 13 de maio de 1944, Trento, a minha cidade, sofreu um terrível bombardeio, um dos muitos. Com as minhas companheiras, um dia nos protegemos num subterrâneo escuro, com a vela acesa e o Evangelho nas mãos. Eu o abri e li a oração de Jesus antes de morrer: «Pai, que todos sejam um» (Jo 17,21). Essas palavras colocaram no coração a convicção de que tínhamos nascido para realizar aquela página do Evangelho.

Os bombardeios continuavam e, com eles, desapareciam aquelas coisas ou pessoas que formavam um pouco o Ideal dos nossos jovens corações. Desmoronaram as possibilidades de formar uma família porque o noivo não voltou do campo de batalha, de prosseguir os estudos, de ter uma casa e assim por diante. A lição que Deus nos oferecia com as circunstâncias era clara: «Tudo é vaidade» (Ecl 1,2). Tudo passa. Nasceu, no meu coração, uma pergunta: «Mas será que existe um ideal ao qual dedicar a nossa vida, que nenhuma bomba possa destruir»? E logo chegou a resposta: «Sim, existe». «É Deus». Eu e as minhas companheiras decidimos fazer de Deus o por quê da nossa vida. Mas quem é Deus?

Ao pronunciarmos o seu nome, no céu da nossa alma, como por uma fulguração, compreendemos, ou melhor, voltamos a compreender que Deus é Amor. E daquele momento em diante nos sentimos envolvidas pelo seu amor. Antes também sabíamos que Deus existia, mas era imaginado por nós distante, além das estrelas, inacessível. Depois tudo havia mudado. Era como se os nossos olhos tivessem sido abertos para ver que Deus, porque é Amor, estava perto de nós, acompanhava cada nosso passo, escondia-se sob todas as circunstâncias da vida, alegres ou tristes. Ele sabia tudo de nós. E acreditar em "Deus Amor" tornou-se o primeiro ponto fundamental da nova espiritualidade.

Mas se Deus é Amor - pensávamos -, qual deve ser a nossa atitude perante Ele? A vida de Jesus foi esclarecedora para nós: Ele amou o Pai fazendo a sua vontade. Assim também nós devemos agir. Fazer a vontade de Deus é o segundo ponto fundamental da nossa espiritualidade.

As bombas caíam de dia e de noite, obrigando-nos a correr, até onze vezes ao dia, para o abrigo antiaéreo e não podíamos levar nada conosco além de um pequeno livro: o Evangelho. Nele - estávamos certas - teríamos encontrado aquilo que Jesus queria, a sua vontade. Nós o abríamos e aquelas palavras se iluminavam completamente. Nós as compreendíamos como se fosse pela primeira vez e uma força que, provavelmente, vinha do Espírito, impelia-nos a colocá-las em prática. 
Líamos: «Ama o teu próximo como a ti mesmo» (Mt 19,19). O próximo! Onde estava o próximo? Eram todas aquelas pessoas afligidas pela guerra que tinham fome, sede, estavam feridas, sem roupas, sem casa. E logo nos dedicávamos a elas. O Evangelho nos garantia: «Pedi e recebereis» (Mt 7,7). Pedíamos algo para os pobres e recebíamos sem falta muitas coisas, que distribuíamos a quem precisava.

Agora devo me deter para contar algo que não está no texto, pois uma personalidade, aqui presente, assim me pediu. É um episódio. Ainda naquele período um pobre se aproximou de mim e me disse: «Chiara, preciso de um par de sapatos número 42». Encontrar sapatos no período de guerra era impossível, ainda por cima número 42. Lembro que entrei na igreja e me ajoelhei diante do tabernáculo. Sabendo que Jesus está presente nos pobres eu disse: «Jesus, eu preciso de um par de sapatos número 42 para você naquele pobre»! Saí da igreja e uma moça se aproximou de mim e me disse: «Chiara, isso é para os seus pobres». Eu o abri e era um par de sapatos número 42.

«Dai e vos será dado» (Lc 6,38), líamos ainda. Dávamos. Um dia havia em casa uma única maçã. Nós a demos ao pobre que pedia. E na mesma manhã chegou uma dúzia de maçãs, que demos também e à noite chegou uma bolsa cheia de maçãs. Jesus havia prometido e mantinha. O Evangelho, portanto, era verdadeiro. Essa constatação nos fazia voar no caminho que tínhamos acabado de tomar. Comunicávamos, aos outros, o que nos acontecia e eles, encontrando-nos, sentiam que encontravam Jesus vivo.

Atuar a Palavra de Deus é o terceiro ponto da nossa espiritualidade. Todas as Palavras de Jesus nos impressionaram. Logo, porém, o Espírito Santo foi destacando para nós aquelas que se referiam ao amor, ao amor evangélico. E viver o amor foi mais um ponto fundamental da nossa espiritualidade. Porém, dado que estávamos sempre diante da morte, um dia nos perguntamos: Mas existirá uma vontade de Deus que Ele ama particularmente? Gostaríamos de colocar em prática exatamente essa, antes de morrer.

No Evangelho, havia um mandamento que Jesus tinha definido "seu" e "novo". Era o que procurávamos: Este é o meu mandamento. Amai-vos uns aos outros, como eu vos amei. Ninguém tem maior amor do que aquele que dá a vida pelos seus amigos (Jo $15,12-13)$.Nós o vivemos, aliás, o exprimimos num pacto. Olhamos uma para a outra e declaramos: "Eu estou pronta a morrer, por você; eu por você; eu por você". Cada uma por todas. Daquele momento em diante, a nossa vida mudou. O que havia acontecido? Com esse ato, colocamos em ação a caridade recíproca. E o amor nos tinha unido como Jesus havia desejado, quando disse: «Onde dois ou mais estiverem reunidos no meu nome - os padres da Igreja dizem 'no meu amor' -, ali estou eu no meio deles» (Mt 18,20). Jesus se colocou entre nós. E tudo o que era novo, belo, luminoso, no nosso coração, era efeito da sua presença. Amor recíproco e Jesus em meio, outros pontos da nossa espiritualidade. 
Mas nem sempre conseguíamos viver assim. Por vezes, defeitos até pequenos ofuscavam o esplendor da nossa unidade. O Evangelho, porém, podia nos ensinar a enfrentar também estes momentos. Por uma circunstância, viemos a saber que Jesus havia atingido o ápice do sofrimento quando, na cruz, experimentando inclusive o abandono do Pai, gritou: «Meu Deus, meu Deus, por que me abandonaste» (Mt 27,46). Esse fato nos comoveu. Desde então decidimos seguir, ao longo da nossa vida, Jesus abandonado. Descobrimos em toda parte o seu semblante e o amamos: nos sofrimentos pessoais, nas pessoas sós, como Jesus, abandonadas, sofredoras, nas divisões do mundo. Jesus crucificado e abandonado é outro aspecto muito importante da nossa espiritualidade. Mas Jesus não havia dito: «Nisto conhecerão todos que sois meus discípulos, se tiverdes amor uns aos outros»? (Jo 13,35)? Ele não disse: «Que sejam um para que o mundo creia» (Jo 17,21)?

Quem estava ao nosso redor sentia reanimar a sua fé e voltava a acreditar ou acreditava pela primeira vez em Jesus. Com o amor recíproco, que gerava Jesus entre nós, estávamos prontas a atuar a unidade invocada por Jesus: «Que sejam um como eu e tu» (cf Jo 17,21). A unidade é outro ponto da nossa espiritualidade.

Estas são algumas linhas da nossa Obra do ponto de vista espiritual. Mas o nosso Movimento pode ser visto também sob o prisma teológico, filosófico, cultural, social, econômico, educativo, artístico, assim como ecumênico e interreligioso. Vou tentar expor algumas das consequências pedagógicas dos mais significativos pontos dessa espiritualidade.

De fato, o nosso Movimento e a nossa história podem ser vistos como um grande e extraordinário evento educativo. Nele, estão presentes todos os fatores da educação e também é evidente a presença de uma teoria da educação, de uma pedagogia bem delineada que fundamenta a nossa ação educativa. Mas - perguntemo-nos, imediatamente, - o que é a educação?

Ela pode ser definida como o itinerário que o educando (indivíduo ou comunidade) percorre, com a ajuda do educador ou dos educadores, na direção de um dever-ser, de um objetivo considerado válido para o homem e para a humanidade. E quais são os elementos característicos da nossa pedagogia ligados, como eu disse, aos pontos principais da espiritualidade que vivemos?

Se considerarmos o primeiro ponto, a revelação de Deus como Amor que passe na sua palavra, podemos constatar que, na nossa história, desde o seu início, esteve presente um único educador, o Educador por excelência, justamente Ele: Deus Amor, Deus Pai. Foi Ele quem tomou a iniciativa em relação a nós, que nos acompanhou, nos renovou, nos regenerou - com a intencionalidade que anima o verdadeiro educador - ao longo de um riquíssimo itinerário de formação pessoal e comunitária. 
Foi Ele quem nos fez recuperar (a nós e a muitos) o sentido da maior Paternidade que existe: uma descoberta de alcance enorme e imaginem que certa cultura em voga tenta afirmar - no plano teórico e prático - que "Deus está morto". Eclipse do Pai que favoreceu também um eclipse da figura do pai, o qual perdeu a autoridade no plano dos relacionamentos humanos e educativos, favorecendo um relativismo moral, a ausência de regras na vida individual, nas relações interpessoais e sociais. Muitas vezes com consequências graves, tal como formas de violência, etc., quase dando razão a Dostoievski, quando afirma que «matar Deus é o mais horrível suicídio»... e também «se Deus não existe, então tudo é permitido».

Nós tivemos a graça de conhecer Deus. Ele, que é Amor, não é por nada um juiz distante, um inimigo ciumento que esmaga com a sua potência o homem ou não se preocupa com ele. Pelo contrário, é um educador que reconhece o homem na sua identidade única e irrepetível, que exalta o homem. Ele ama o homem e por isso é exigente com ele. Como verdadeiro educador, Deus exige a responsabilidade e educa ao empenho.

Deus é Amor e por isso nos libertou da escravidão mais cerrada, reabrindo para nós as portas de sua Casa. E sabemos qual foi o preço que seu Filho pagou por esse resgate. Nenhum educador jamais considerou tanto o homem quanto um Deus que morreu por ele. Deus Amor elevou o homem, cada homem, à altíssima dignidade de filho e herdeiro. Cada homem!

E é exatamente a constatação de que todos somos filhos do mesmo Pai que se fundamenta a ideia principal de Comenio, grande representante da pedagogia moderna que disse: "é preciso ensinar tudo a todos".

Outro ponto fundamental da nossa espiritualidade é a Palavra de Deus. «Ensinar tudo a todos», foi dito, mas para isso é necessário usar - como dizia o próprio Comenio - a regra pedagógica da graduação. Pensando bem, o Pai sugeriu essa graduação a nós, focolarinas, quando, desde os primeiros dias, nos impeliu a viver a sua Palavra, escolhendo do Evangelho uma frase de cada vez, a ser colocada em prática por um mês, na vida do dia a dia. Mas com isso nos deu logo "Tudo", porque em cada Palavra está presente Jesus por inteiro; ao mesmo tempo, como crianças nutridas pela sua Palavra, fomos nos revestindo cada vez mais dela, crescendo como adultos na fé e na vida. E com esta simplicíssima técnica pedagógica da graduação e da totalidade, a luz do nosso Ideal se difundiu e continua a difundir-se até onde não podemos imaginar, como experiência espiritual e educativa forte e em contínua expansão.

A unicidade da Palavra de Deus, ainda, é que ela é Palavra de Vida, de que se faz experiência, em um mundo, também pedagógico, muitas vezes poluído de verbosidade. Experimentamos a força educativa, alternativa e contestatária, dessa Palavra sempre viva e sempre nova. Pouco a pouco, impressa na nossa vida, ela lhe conferiu - função imensa e própria da educação - uma unidade existencial, favorecendo a superação da fragmentação, 
-desmembramento que o homem muitas vezes experimenta na sua relação consigo mesmo, com o outro, com a sociedade, com Deus, fazendo emergir, a um só tempo, a unicidade, a originalidade de cada um.

E é graças a esta unidade existencial entre Palavra e Vida, entre dizer e fazer, que a nossa experiência é, para muitos, digna de crédito e convencedora, provocando profundas mudanças na existência pessoal, acionando em muitas pessoas um verdadeiro processo educativo.

A vontade de Deus, outro ponto. A fidelidade à Palavra de Deus nos acostumou também a "perder a nossa má vontade", aquela que ainda nos liga às estreitas modalidades existenciais do eu centralizado em si e a seguir a vontade de Deus, que nos conduz, continuamente, à auto transcendência, que nos leva a ultrapassarmos o nosso eu na direção de um Tu que nos enriquece e liberta.

É normativo, na educação moral da pessoa, que se passe da necessária fase inicial de dependência ${ }^{1}$, gradualmente, à moralidade autônoma ${ }^{2}$. Também na nossa experiência, percebemos a passagem educativa da inicial adesão a uma vontade alheia, à sua Lei (que se manifesta de várias maneiras) - à qual nos agarramos como uma criança que se entrega totalmente à direção do adulto -, percebemos uma passagem para a forte percepção de liberdade pela interiorizarão da Lei em si, quando sentimos que ela se tornou a nossa lei, quando ela está tão gravada em nós a ponto de nos fazer sentir adultos exatamente porque capazes de dizer: «Já não sou eu que vivo, é Cristo que vive em mim» (G1 2,20).

E ainda: Jesus que grita: «Meu Deus, meu Deus, por que me abandonaste?» (Mt 27,46; Mc 15,34).--Jesus abandonado-- é o nosso segredo, a nossa ideia-chave, também para a educação. Ele nos indica o limite sem limites da nossa ação pedagógica; até a que ponto e com que intensidade ela deve se mover?

Quem é Jesus abandonado, por quem decidimos ter um “amor preferencial"? Ele é a figura do ignorante, pois pergunta “por quê?” (a sua é a ignorância mais trágica, a pergunta mais dramática); é a figura do excluído, do desadaptado, do portador de deficiência, do não amado, do neglicenciado, do marginalizado, de todas aquelas realidades e experiências humanas e sociais que exigem, mais do que outras, uma urgente e especial necessidade de educação. Jesus abandonado é o paradigma de quem, carente de tudo, precisa de alguém que lhe dê tudo e por Ele faça tudo. Portanto, é também a ideia limite, o parâmetro do educando, que postula a responsabilidade do educador. Ele nos indica, portanto, o limite sem limites dessa necessidade e, ao mesmo tempo, o limite sem limites da nossa responsabilidade em ajudar e educar.

1 Moralidade heteronômica

2 Que deveria caracterizar o sujeito adulto e maduro; 
Jesus abandonado, porém, que superou a sua infinita dor acrescentando: «Em tuas mãos, Pai, entrego o meu espírito» (Lc 23,46), nos ensina também a ver a dificuldade, o obstáculo, a provação, o compromisso, o erro, o fracasso, o sofrimento, como algo a ser enfrentado, amado, superado. Geralmente nós, homens, em qualquer campo de atividade, tentamos evitar com todos os meios tais experiências. Também no campo educativo, de várias maneiras, com formas de superproteção, tende-se a preservar as crianças de qualquer forma de dificuldade, habituando-as a ver a vida como uma estrada em descida, fácil e cômoda. Na realidade as deixamos despreparadas para enfrentar as inevitáveis provações da vida e, sobretudo, as tornamos passivas e renitentes perante as responsabilidades que cada ser humano deve assumir diante de si, do próximo, da sociedade. Para nós, ao invés, exatamente pela escolha de Jesus abandonado, cada dificuldade deve ser amada e enfrentada. A educação à dificuldade, como compromisso que envolve o educando e o educador é, portanto, outro ponto fundamental da nossa pedagogia.

Existem outros dois pontos que desejo tomar em consideração: a unidade e Jesus em meio. Aqui, poderíamos nos perguntar qual é a finalidade do processo educativo? A nossa é a mesma finalidade de Jesus cuja finalidade educativa poderia ser definida com o «que todos sejam um», a unidade, portanto, profunda e sincera, com Deus e entre os homens.

A unidade é uma aspiração muito atual. Apesar das inumeráveis tensões do mundo contemporâneo, o nosso planeta, quase paradoxalmente, tende à unidade: a unidade é um sinal e uma necessidade dos tempos.

Todavia, este íntimo impulso - como no e-ducere (extrair) da educação -, deve vir à tona positivamente. Nisso, portanto, está implicada, em todos os planos do agir humano, uma ação educativa coerente com as exigências da unidade, para fazer do nosso mundo não uma Babel sem alma, mas uma experiência de Emaús, de Deus conosco, capaz de abraçar a humanidade inteira. Parece um projeto utópico, mas cada pedagogia autêntica é portadora de um objetivo utópico, a ser entendido como uma ideia reguladora que constitui entre nós aquela sociedade que ainda não existe, mas que deveria existir. A educação, nessa perspectiva, é vista como meio para nos aproximarmos do objetivo utópico.

Na nossa pedagogia, por meio da qual, o plano espiritual e humano se compenetram e se unificam (pela encarnação), a Utopia não é um sonho, nem ilusão, nem meta inatingível. Ela está entre nós e colhemos os seus frutos, quando atualizamos o «onde dois ou mais estiverem reunidos no meu nome, ali estou eu no meio deles». Isso faz com que a finalidade, a meta mais alta, seja realidade.

Aqui experimentamos a plenitude da vida de Deus, que Jesus nos doou, uma relação trinitária, a Socialidade mais autêntica, onde se realiza uma síntese maravilhosa entre a instância pedagógica da educação do indivíduo e a instância pedagógica da construção 
da comunidade. Acreditamos que, na nossa experiência de espiritualidade comunitária trinitária, realizem-se, plenamente, as ideias defendidas por tantos expoentes da história da pedagogia, mesmo partindo, frequentemente, de premissas diferentes, insistiram sobre a importância da educação para a construção da sociedade fundamentada nos relacionamentos autenticamente democráticos. Pensamos, só para citar um nome, na grande contribuição ao mundo pedagógico oferecido, a partir dos Estados Unidos, por John Dewey. Encontramos muitas consonâncias também com a recente "pedagogia social", em que é proclamada a necessidade de conjugar a promoção do indivíduo e a promoção da comunidade.

Naturalmente, a nossa experiência de vida comunitária se baseia no convite de Jesus: «amai-vos como eu vos amei... Sede uma coisa só». Essa motivação é de natureza religiosa, mas são extraordinários os seus efeitos no plano educativo. A finalidade desde sempre delegada à educação (formar o homem, a sua autonomia) explicita-se, quase paradoxalmente, em formar o homem-relação, que para nós é o homem, icone da Trindade, capaz de realizar uma auto-transcendência contínua na realidade de Jesus em meio. É por meio dessa praxe espiritual e educativa do amor recíproco, do consumar-nos em umpraxe que é seguida por todos os membros do Movimento, chamados a viver a experiência comunitária em pequenos grupos, que trabalhamos por aquela finalidade das finalidades, expressa na oração-testamento de Jesus: «Que todos sejam um». É uma utopia-realidade, com instrumentos guiados por Ele, pela qual pretendemos gastar a nossa vida. E é através de uma educação séria que podemos nos tornar, como indivíduos e como comunidade, capazes de colaboração, de diálogo, de encontro com outras pessoas, com outros Movimentos etc. É por meio de uma educação séria, enfim, que - com a graça de Deus - podemos almejar a santidade pessoal e comunitária.Maria é o exemplo de quem vive de modo excelso os pontos pedagógicos referidos.

Naturalmente Jesus, que soube realizar este itinerário pedagógico, este vaivém, por assim dizer, entre o abandono e a Trindade e que, na sua experiência terrena, viveu, com intensidade excelsa, a relação interpessoal, praticando a empatia, a aceitação, a esperança, a luta educativa, a vida de unidade com o Pai, e "com os seus" é Ele o testemunho mais autêntico e mais exigente do que significa ser educadores.

Personalidades presentes, prezados amigos, espero que estes flashes tenham sido suficientes para explicar a experiência pedagógica que emerge do nosso Movimento e possam demonstrar que grande alegria e honra me deram este diploma em pedagogia.

Obrigada pela atenção dispensada. Que Jesus Mestre forme em todos nós verdadeiros e válidos educadores. 